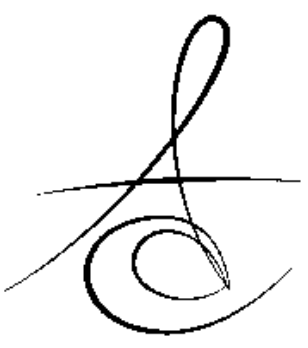

\title{
ÜNİVERSAL ADEZİVLERİN MİNEYE BAĞLANMA DAYANIMININ DEĞERLENDİRİLMESİ
}

\section{EVALUATION OF ENAMEL BOND STENGTH OF UNIVERSAL ADHESIVES}

\author{
Dr. Öğr. Üyesi Muhammet KARADAŞ* \\ Arş. Gör Ömer HATİPOĞLU* \\ Dr. Öğr. Üyesi Sabit Melih ATEŞ ${ }^{* *}$
}

Makale Kodu/Article code: 3261

Makale Gönderilme tarihi: 03.01.2017

Kabul Tarihi: 29.03.2017

\section{öz}

Amaç: Bu çalışmanın amacı dört farklı üniversal adezivin mineye makaslama bağlanma dayanımını iki aşamalı bir self-etch adezivle karşılaştırmalı olarak incelemektir.

Gereç ve Yöntem: 100 adet sağlam üçüncü molar diş bukkal ve lingual iki parçaya bölündü. Örnekler adeziv ajanlara göre rastgele 5 gruba ayrıldı; OptiBond XTR, Clearfil Universal Bond, All Bond Universal, Single Bond Universal, Clearfil SE Bond. Düzleştirilmiş mine yüzeylerine herbir adeziv ajan self-etch ya da totaletch yöntemleri kullanılarak uygulandı ve kompozit rezin yerleştirildi. Örnekler 24 saat $37^{\circ} \mathrm{C}$ 'de distile su içerisinde bekletildikten sonra ya da 5.000 termal siklus uygulandıktan sonra makaslama bağlanma testine maruz bırakıldı. Veriler 3 yönlü varyans analizi ve Tukey post-hoc testi $(p=0.05)$ kullanılarak analiz edildi.

Bulgular: İstatistiksel sonuçlar adeziv ajanın tipi ve uygulama yönteminin mineye bağlanma dayanıklılı̆ını önemli derecede etkilediğini gösterdi ( $p<0.001)$. Termal siklus mineye makaslama bağlanma dayanıkıılı̆ını etkilemedi ( $p>0.05$ ). Total-etch yöntemi ile elde edilen taranmış elektron mikroskop görüntüleri uzun rezin tagları ve iç içe geçmiş polimerik ağları göstermektedir.

Sonuç: Self-etch tekniği ile Clearfil SE Bond, üniversal adezivlerden daha fazla mineye makaslama bağlanma dayanıklılı̆ı gösterdi. Uygulama tekniğine bakılmaksızın üniversal adezivlerin mineye bağlanma dayanıklıkları arasında önemli bir farklılık bulunamadı. Mineyi asitleme tüm adezivlerin makaslama bağlanma dayanıklıı̆̆ını önemli derecede arttırdı.

Anahtar kelimeler: Bağlanma dayanımı, diş minesi, dental adezivler, universal adeziv, total-etch tekniği

\section{ABSTRACT}

Aim: The aim of this study was to evaluate the shear bond strength of four universal adhesives to enamel compared to two-step self-etch adhesive.

Material and Methods: One hundred human third molars were sectioned into two fragments (buccal and lingual) and randomly assigned to five groups according to adhesive agents (OptiBond XTR, Clearfil Universal Bond, All Bond Universal, Single Bond Universal, and Clearfil SE Bond). Each adhesive agent was applied to a flattened enamel surface by using the self-etch or etch-and-rinse strategy, and the composite resin was constructed onto the bonded enamel surface. The specimens were stored for $24 \mathrm{~h}$ in $37^{\circ} \mathrm{C}$ distilled water or were thermocycled for 5,000 cycles. Then shear bond strength testing was performed. Data were analyzed using three-way analysis of variance and the Tukey post-hoc test ( $p=0.05$ ).

Results: The type of adhesive agent and application strategy had a significant effect on the enamel bond strength $(p<0.001)$. The thermocyling process did not significantly affect the shear bond strength to enamel ( $p>0.05)$. Scanning electron microscopy images obtained with the etch-and-rinse strategy showed long resin tags and an interpenetrated polymeric network.

Conclusion: Clearfil SE Bond with self-etch strategy had significantly higher shear bond strength to enamel than did the universal adhesives. No significant differences were found among the enamel bond strengths of studied universal adhesives regardless of application strategy. The pre-etching treatment of enamel significantly improved the shear bond strength of all of the adhesives tested.

Key words: Bond strength, enamel, adhesives.

* Recep Tayyip Erdoğan Üniversitesi, Diş Hekimliği Fakültesi, Diş Hastalıkları ve Tedavisi, Rize

${ }^{* *}$ Recep Tayyip Erdoğan Üniversitesi, Diş Hekimliği Fakültesi, Protetik Diş Tedavisi, Rize.

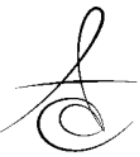




\section{GİRIŞ}

Mine ve dentine bağlanma ilk olarak 1955 yılında Buoncore tarafından gündeme getirilmiştir. Geçmişten günümüze kadar adezivler yapısındaki değişimlerle birlikte uygulama tekniği ve bağlanma etkinliği açısından dereceli olarak gelişmiştir. Son 20 yılda adeziv ajanların yedi jenerasyonu tanıtılmıştır. Son zamanlarda farklı restorasyon prosedürleri için üniversal ya da çok amaçlı adezivler geliştirilmiştir. Bu adeziv ajanlar etch-and-rinse, selektif etch ve self-etch adeziv olarak kullanılabilir. ${ }^{1,2}$

Adeziv ajanların kullanılmasındaki temel amaç diş yüzeyi ile restoratif materyal arasında tam bir adaptasyonun sağlanmasıdır. Mine ve dentinin yapısal farklılıklarına rağmen adeziv sistemler bu iki yüzeye de eşit düzeyde bağlanabilme kapasitesine sahip olmaIıdır. ${ }^{3}$ Adeziv ajanların mine ve dentine genel bağlanma mekanizması yüzeyel demineralizyona bağlıdır. Rezin monomerlerin yüzeydeki porözitelere infitrasyonu ve sonra polimerizasyonu ile hibrit tabakası oluşur. Dentin tübülleri içine uzanan rezin tagları bir mikromekaniksel bağlanma oluşturur. ${ }^{4} \mathrm{Bu}$ hibrit tabakası postoperatif hassasiyeti azaltabilir, iyi bir kenar uyumu temin edebilir ve yerleştirilen kompozit rezinin büzülme streslerini kompanse edebilir. ${ }^{2,5}$, 6 Nemli ve organik yapısından dolayı dentine bağlanma mineye kıyasla oldukça zordur. ${ }^{2}$

Adeziv sistemler diş sert yapılarına bağlanma tekniğine göre 2 temel kategoride sınıflandırılabilir: etch-and-rinse, self-etch adezivler. ${ }^{4}$ Etch-and-rinse adezivlerinde mine ve dentindeki smear tabakasını kaldırmak ve daha fazla yüzeyel hidroksiapatit kristallerini demineralize etmek için fosforik asit uygulanır. Bu yöntem genellikle minede kullanılır ve minede maksimum tutuculuk sağlamak için gereklidir. ${ }^{7}$ Fakat diş yapısının uzun süre asitlenmasi, aşırı kurutulması ya da fazla nemli bırakılması etch-and-rise adezivlerin önemli dezavantajıdır. ${ }^{8}$ Her ne kadar diş sert dokularına adezyon için etch-and-rinse adezivler altın standart olarak gösterilsede, günümüzde yaygın trend basitleştirilmiş self-etch adezivlerin geliştirilmesi yönündedir. ${ }^{9}$

Self-etch adezivler tek aşamalı veya iki aşamalı (hidrofilik primer ve hidrofobik adeziv) olarak kullanılabilmektedir. Self-etch adezivler ayrıca bir asit uygulaması içermezler ve fosforik asitin oluşturduğu gibi minede derin poröziteler oluşturmazlar. ${ }^{10}$ Bundan dolayı çoğu self-etch adeziv sistem kristallerin arasına rezin monomerlerin sığ bir infiltrasyonunu sağlarlar ve prizmalar arası rezin-tagları oluşturmazlar. ${ }^{11}$ Self-etch adezivler smear tabakasını kaldırmadan alttaki yüzey tabakası ile bağlanır. ${ }^{12}$ Mineye asit uygulanmadığında üniversal veya self-etch adezivlerin bağlanma dayanıklıklarının düşük olduğu rapor edilmiştir. ${ }^{13,}{ }^{14}$. Bundan dolayı bazı çalışmalarda mine sınırlarına selektif asitleme uygulanması tavsiye edilmiştir. ${ }^{15,16}$

Bazı üretici firmalar çok yönlü üniversal adezivleri piyasaya sunarak diş hekimlerine farklı adeziv stratejilerini kullanma noktasında seçenekler sunmuşlardır. Bu çalışmanın amacı, 4 farklı üniversal adezivi 2 farklı bağlama yöntemi (self-etch, etch-and-rinse) ile uygulayarak mine yüzeyine makaslama bağlanma dayanımını konvensiyonel bir self-etch adezivle karşılaştımalı olarak değerlendirmektir.

\section{GEREÇ VE YÖNTEM}

$\mathrm{Bu}$ çalışmada ortodontik ve oral cerrahi sebeplerden dolayı çekilmiş 100 adet çürüksüz üçüncü büyük azı dişi kullanıldı. Dişler \%0.5 kloramin-T solüsyonunda 48 saat boyunca dezefente edildi ve kullanılana kadar distile suda bekletildi. Dişlerin kronları mezio-distal yönde elmas separe ile ikiye bölündü ve bukkal ve lingual parçalar elde edildi. Örnekler mine yüzeyi dişarda olacak şekilde kimyasal olarak sertleşen akrilik rezinin içerisine gömüldü. Mine yüzeyleri elmas frez kullanılarak düzleştirildi ve daha sonra standart bir smear tabakası oluşturmak için 600-grit silikon zımpara ile 30 saniye süresince uyguland.

Örnekler kullanılan adeziv materyallere (Single Bond Universal, All Bond Universal, Clearfil Universal Bond, OptiBond XTR ve Clearfil SE Bond) göre rastgele 5 gruba ayrıldı $(n=40)$. Bu adeziv materyallerin kompozisyonları üretici firmaların belirttiği şekilde Tablo 1'de gösterilmiştir. Her bir adeziv materyal gruptaki örneklerin yarısına Self-etch tekniği kullanılarak ve diğer yarısına Etch-and-rinse tekniği kullanılarak mine yüzeyine uygulandı. Etch-and-rinse tekniğinde \%32 fosforik asit (3M ESPE) mine yüzeyine 15 saniye boyunca uygulandı. Sonra tüm mine yüzeyi 15 saniye boyunca distile ile yıkandı ve 3 saniye hafifçe hava spreyi ile kurutuldu. Her bir adeziv materyal üretici firmaların talimatlarına göre mine yüzeyine uygulandı. Mine yüzeyine uygulanan adeziv ajanın polimerizasyonundan önce $2 \mathrm{~mm}$ iç çapında ve $2 \mathrm{~mm}$ yüksekliğinde taygon tüpü yerleştirildi ve sonra adeziv ajan LED 
(light-emittin diod) ışık kaynağı ile polimerize edildi. Üniversal bir kompozit (Filtek Z250, 3M ESPE; Saint Paul, Minnesota, USA) taygon tüpünün içerisine $2 \mathrm{~mm}$ yüksekliğe kadar kondanse edildi. Kompozit rezin 1000 $\mathrm{mW} / \mathrm{cm}^{2}$ ışık gücünde 40 saniye boyunca LED ışık kaynağı (VALO Cordless; Ultradent, South Jordan, Utah, USA) ile polimerize edildi. Kompozit diş örnekleri distile suda 24 saat boyunca $37^{\circ}$ 'de saklandı ve sonra taygon tüpleri dikkatlice çıkarıldı. Self-etch ya da etchand-rinse tekniği ile hazırlanan örnekler ikiye ayrıldı. İlk gruptaki örnekler taygon tüplerinin çıkarılmasından hemen sonra ve ikinci gruptaki örnekler 5.000 termal siklus işleminden sonra makaslama bağlanma testine maruz bırakıldı. Termal siklus örneklerin $5^{\circ} \mathrm{C}$ ve $55^{\circ} \mathrm{C}^{\prime}$ deki banyoların herbirinde $15^{\prime}$ er saniye bekletilmesiyle gerçekleştirildi. Makaslama bağlanma dayanıklıık testi için örnekler 3344 Üniversal test cihazına (Instron Corporation, Norwood, Massachusetts, USA) yerleştirildi (Resim 1). Kompozit-mine ara yüzüne bağlantı kırılıncaya kadar $0.5 \mathrm{~mm} / \mathrm{dk}$ kafa hızında kuvvet uygulandı. Newton değerindeki sonuçlar megapaskala (MPa) çevrildi.

Tablo 1. Kullanılan adeziv ajanlar ve içerikleri

\begin{tabular}{|l|l|}
\hline Adeziv (Üretici) & İçerik (Lot no) \\
\hline $\begin{array}{l}\text { OptiBond XTR } \\
\text { (Kerr Corp., USA) }\end{array}$ & $\begin{array}{l}\text { Primer: Acetone, ethanol, HEMA (LG02092) } \\
\text { Adhesive: Ethyl alcohol, barium-alumino- } \\
\text { boro-silicate chemicals, silicon dioxide, } \\
\text { HEMA, sodium silicofluoride, silanamine } \\
\text { (LG02093) }\end{array}$ \\
\hline $\begin{array}{l}\text { Clearfil Universal Bond } \\
\text { (Kuraray, Japan) }\end{array}$ & $\begin{array}{l}\text { Bis-GMA, 10-MDP, HEMA, hydrophilic } \\
\text { aliphatic dimethacrylate, silane coupling } \\
\text { agent, colloidal silica, camphorquinone, } \\
\text { ethanol, accelerators, initiators, water } \\
\text { (100004) }\end{array}$ \\
\hline $\begin{array}{l}\text { All Bond Universal } \\
\text { (Bisco Inc., USA) }\end{array}$ & $\begin{array}{l}\text { Bis-GMA, HEMA, 10-MDP, ethanol, initators, } \\
\text { water (1400006251) }\end{array}$ \\
\hline $\begin{array}{l}\text { Single Bond Universal } \\
\text { (3M ESPE, USA) }\end{array}$ & $\begin{array}{l}\text { HEMA, 10-MDP, silane, dimethacrylate } \\
\text { resins, initiators, methacrylate modified } \\
\text { polyalkenoic acid copolymer, filler, ethanol } \\
\text { (521196) }\end{array}$ \\
\hline $\begin{array}{l}\text { Clearfil SE Bond } \\
\text { (Kuraray, Japan) }\end{array}$ & $\begin{array}{l}\text { Primer: HEMA, 10-MDP, dl- } \\
\text { Camphorquinone, water, hydrophilic } \\
\text { aliphatic dimethacrylate (A40053) } \\
\text { Adhesive: Bis-GMA, HEMA, MDP, collodial } \\
\text { silica, hydrophilic aliphatic dimethacrylate, } \\
\text { dl-Camphorquinone, Initiators, Accelerators } \\
\text { (A70085) }\end{array}$ \\
\hline $\begin{array}{l}\text { Bis-GMA: Bisphenol A-glycidyl methacrylate; HEMA: 2-hydroxylethyl } \\
\text { methacrylate; MDP: 10-methacryloxydecyl dihydrogen phosphate. }\end{array}$ \\
\hline
\end{tabular}

\section{Elektron Mikroskop Taraması}

Adeziv tabakalarını elektron mikroskop (SEM) kullanılarak incelemek için yukarıda tanımlandığı gibi örnekler hazırlandı. Her bir adeziv ajan self-etch ya da etch-and-rinse tekniği kullanılarak mine yüzeyine uy-

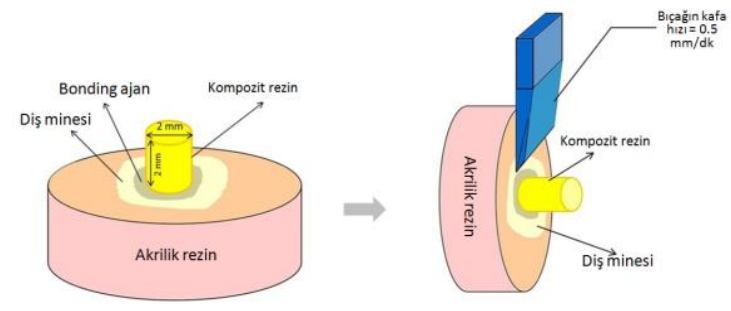

Resim 1. Makaslama bağlanma dayanımını ölçmek için çalışma tasarımı

gulandı. Mine yüzeyi kompozit rezinle kapatıldı ve kompozit rezin polimerize edildi. Kompozit-diş örenekleri 24 saat boyunca distile suda saklandı. Diş yapısını çözmek için örnekler $6 \mathrm{~N} \mathrm{HCI}$ içerisinde 24 saat bekletildi. Sonra örnekler distile su ile yıkandı ve ardından örneklere 10 dakika \%5 NAOCI solüsyonu uygulandı. ${ }^{17}$ Örnekler kurutulduktan sonra 20 kV'de SEM (JSM- 6610; JEOL, Peabody, Massachusetts, USA) kullanılarak adeziv materyallerin hibrit tabakaları incelendi.

Adeziv ajanların, uygulama yöntemlerinin (Etchand-rinse ve self-etch) ve termal siklusun ma- kaslama bağlanma dayanıklıı̆ı üzerine etkilerini belir- lemek için üç yönlü varyans analizi ve Tukey testi kullanıldı İstatistik anlamlılık için $\mathrm{p}<0.05$ yeterli kabul edilmiştir.

\section{BULGULAR}

Adeziv ajanların mineye makaslama bağ- lanma dayanıklılık değerleri ve standart sapmaları Tablo 2'de gösterilmiştir. İstatistiksel analizin sonuçları adeziv ajan arın ve uygulama yöntemlerinin makaslama bağlanma dayanımında önemli bir etkiye sahip olduğunu gösterdi $(p<0.001)$, fakat termal siklus bağlanma dayanımını etkilemedi $(p=0.61)$. Etch-and-rinse tekniği kullanıldığı zaman adezivlerin 24 saat sonraki bağlanma dayanımları arasında önemli bir farklılık bulunamadı ( $p>0.05$ ). Thermal siklus sonrası, etch-andrinse tekniği ile yalnızca Clearfil SE Bond ve All Bond Universal arasında önemli bir farklılık bulundu ( $p=$ 0.015). Makaslama bağlanma dayanımı testinin gerçekleştirilme zamanına bakılmaksızın, self-etch tekniği ile Clearfil SE Bond önemli derecede yüksek bağlanma gücüne sahipti. Fakat 24 saat sonra self-etch tekniği ile Clearfil SE Bond ve Single Bond Universal arasında anlamlı bir farklılık bulunamadı $(p=0.062)$. Fosforik asit uygulaması test edilen tüm adeziv ajanların mineye bağlanma dayanımını önemli derecede artırdı $(p<0.05)$. 
Tablo 2. Adeziv ajanların mineye makaslama bağlanma dayanıklılık değerleri ve standart sapmaları

\begin{tabular}{|c|c|c|c|c|}
\hline \multirow[b]{2}{*}{ Adeziv } & \multicolumn{2}{|c|}{ Etch-and-rinse tekniği } & \multicolumn{2}{|c|}{ Self-etch tekniği } \\
\hline & 24 saat & $\begin{array}{l}\text { Termal } \\
\text { siklus }\end{array}$ & 24 saat & \begin{tabular}{|l} 
Termal \\
siklus
\end{tabular} \\
\hline OptiBond XTR & $\begin{array}{c}4.53 \pm 4.65 \\
a\end{array}$ & $\begin{array}{c}22.77 \pm 5.35 \\
a b\end{array}$ & $\begin{array}{c}16.28 \pm 2.91 \\
b\end{array}$ & $16.75 \pm 2.26 b$ \\
\hline $\begin{array}{l}\text { ClearfilUniversal } \\
\text { Bond }\end{array}$ & $\begin{array}{c}22.67 \pm \\
3.35 \mathrm{a}\end{array}$ & $\begin{array}{c}23.89 \pm 2.12 \\
a b\end{array}$ & $\begin{array}{c}17.25 \pm 2.71 \\
b\end{array}$ & $\begin{array}{c}17.32 \pm 3.40 \\
b\end{array}$ \\
\hline All Bond Universal & $\begin{array}{c}21.59 \pm \\
5.22 \mathrm{a}\end{array}$ & $19.92 \pm 4.75$ & $17.03 \pm 3.32$ & $\begin{array}{c}14.63 \pm 3.98 \\
b\end{array}$ \\
\hline $\begin{array}{c}\text { Single Bond } \\
\text { Universal }\end{array}$ & $\begin{array}{c}23.89 \pm \\
3.74 \mathrm{a} \\
\end{array}$ & $\begin{array}{c}24.79 \pm 4.70 \\
a b\end{array}$ & $\begin{array}{c}18.76 \pm 3.23 \\
a b\end{array}$ & $\begin{array}{c}17.02 \pm 3.46 \\
b\end{array}$ \\
\hline Clearfil SE Bond & $\begin{array}{c}25.12 \pm \\
3.74 \mathrm{a} \\
\end{array}$ & $27.45 \pm 4.07 a$ & $\begin{array}{c}1.54 \pm 2.61 \\
a\end{array}$ & $0.78 \pm 3.30 a$ \\
\hline
\end{tabular}

Self-etch ve Etch-and-rinse bağlanma yöntemleri uygulandığındaki mine hibrit tabakalarının SEM görüntüleri Resim 2'de gösterilmiştir. Self-etch ve etch-and-rinse yöntemleri ile uygulanan adeziv ajanlarının oluşturduğu hibrit tabakaları arasında önemli morfolojik farkların olduğu tespit edilmiştir. Self-etch tekniği ile uygulanan OptiBond XTR ve Clearfil SE Bond adezivlerinin görüntülerinde kısa rezin tagların mine yüzeyine penetre olduğu, fakat All Bond Universal, Clearfil Universal Bond ve Single Bond Universal adezivlerde ise rezin tagların oluşmadığı gözlemlenmiştir. Fosforik asit kullanımı sonrası mine yüzeyine uygulanan tüm adezivlerde prizmatik bölgeler arasına uzun rezin tagların penetre olduğu gösterilmiştir.

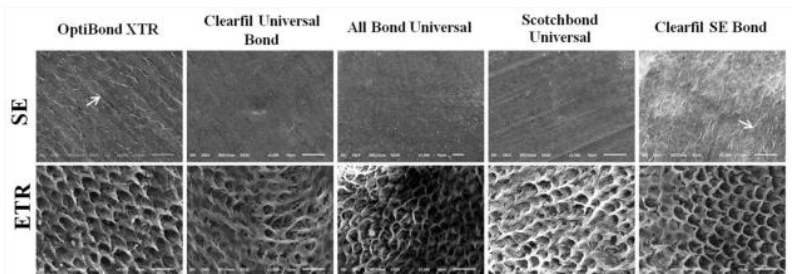

Resim 2. Adeziv ajanların infiltrasyonunun SEM görüntüleri; self-etch (SE) ya da etch-and-rinse (ETR) uygulaması (×1.000-2.000 büyütme).

\section{TARTIŞMA}

Sef-etch adezivleri uygulamadan önce, mineye fosforik asit uygulanmasının daha iyi bir klinik sonuç ve kenar uyumu sağladığı genelllikle kabul edilir. Daha önceki in vitro çalışmalar mineye fosforik asit uygulamasının üniversal adezivlerin bağlanma dayanıklıı̆ını arttırdığını göstermiştir. ${ }^{18,}{ }^{19}$ Bu çalışmada, fosforik asit uygulaması adezivlerin mineye makaslama bağlanma dayanıklıı̆ııı önemli derecede arttırmıştır. Bağlanma dayanıklılığındaki bu artış asitin self-etch adezivlere ek olarak uygulanması ile gelişen mikromekanik kilitlenmeye bağlanabilir. Fosforik asit uygulaması rezin monomerlerin penetrasyonu sınırlayan ya da engelleyen smear tabakasını kaldıır ve her prizmadaki mine kristallerini kademeli olarak çözer. ${ }^{10}$ Sonuç olarak, fosforik asit adeziv rezin monomerlerin mineye infiltrasyonunu artırmakta ve böylece mikromekanik bağlanma artmaktadır. Bu çalışmada, SEM görüntüleri fosforik asit uygulaması ile oluşmuş inter primatik rezin tagları ve adeziv ajanların iç içe geçmiş polimerik ağlarındaki artışı göstermektedir.

Self-etch adezivler diş yüzeyini hem demineralize eden hemde diş yüzeyine infiltre olabilen asidik fonksiyonel rezin monomerler içerir. Self-etch adezivler yalnızca smear tabakasını çözerler ve çözülmemiş kalsiyum fosfatları kaldımazlar. Asidik monomerler smear pöroziteleri arasından ve yüzeyel tabakalar arasından diş yapısına penetre olurlar. ${ }^{4}$ Üniversal adezivler yüksek derecede sofistike karışımlardır ve önceki jenerasyonlarından farklıdırlar. ${ }^{20} \mathrm{Bu}$ çok yönlülük üniversal adezivlerin self-etch, selektif etch ve etch-and-rinse yöntemleri ile tüm diş yapılarında kullanılabilmesine olanak sağlar. Self-etch adezivlerin agresivliği pH değerine bağlıdır. Bu çalışmada OptiBond XTR adezivi dışında, incelenen diğer adezivler ultramild veya mild self-etch adeziv olarak sıniflandırılabilir $(\mathrm{pH} \approx 2-3.2) .{ }^{4}$ Mild self-etch adezivler mine yüzeyinde minimal porözite oluşturmakta ve bu durum prizmalar arasında rezin tagların oluşmamasıyla sonuçlanabilir. ${ }^{17}$ Self-etch primer ajanların mineyi asitleme potansiyeline sahip olduğu gösterilmiştir. Fakat self etch primer uygulaması ile oluşan mine morfolojisi fosforik asit uygulamasının sebep olduğu retantif şablonla kıyaslandığında oldukça yüzeyel ve sığdır. ${ }^{11,21}$ Bu çalışmada, self-etch yöntemi ile self-etch primer içeren OptiBond XTR ve Clearfil SE Bond ile oluşan sığ/ince rezin taglar SEM'de gözlemlenebilmiştir. Fakat OptiBond XTR mineye bağlanma gücü açısından diğer adezivlerle kıyaslandığında önemli bir farklılık göstermedi. Self-etch primerler tarafından oluşturulan bağlanma dayanıkılığının rezin taglarından ziyade daha çok minedeki kristallerin arasında ve kriatallerin içinde oluşan hibridizasyona bağı olduğu bildirilmiştir. ${ }^{22}$

Fosforik asitle mine yüzeyine uygulanan adeziv ajanların bağlanma dayanıkılığı genel olarak kristaller ve prizmalar arasına penetre olan rezin monomerlerle ilişkili olduğu gösterilmiştir. ${ }^{22}$ Asitlenmiş mine yüzeyine rezin monomerlerin tamamlanmamış infiltrasyonu

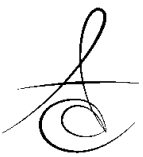


zamanla mineye bağlanma dayanıklılı̆ında azalmaya sebep olabilir. Diğer taraftan, Yoshida ve arkadaşları ${ }^{23}$ tarafından öne sürülen adezyon-dekalsifikasyon teorisine göre, karboksilik asit esaslı, fosfat esaslı ve MDP (10-methacryloyloxydecyl dihydrogen phosphate) monomerleri gibi fonksiyonel adeziv monomerlerin hidroksiapatit kalsiyumları ile kimyasal bağlanma potansiyeline sahip olduğu bildirilmiştir. Fakat bağlanma stabilitesi monomerler arasındaki etkileşiminin doğru moduna bağlıdır ve monomer asiditesi ile ters orantılıdır. MDP monomeri diş yüzeyinde yüzeyel demineralizasyon ve daha stabil bir tuz kompleksi oluşturur. ${ }^{24}$ MDP monomeri erken bağlanma dayanıklılı̆ı üzerinde minumum bir etkiye sahip olmasına rağmen, adezyondekalsifikasyon teorisinin savunucuları kimyasal olarak oluşan tuz komplekslerinin hibrit tabakayı hidrolitik bozulmadan koruyarak bağlanma stablisine katkıda bulunduğunu iddia etmiştir. ${ }^{4}$ Bu çalışmada, adeziv ajanların uygulama tekniği ya da test zamanına bakılmaksızın MDP monomeri kapsayan adezivlerin MDP monomeri kapsamayan OptiBond XTR adezine benzer bağlanma dayanımı gösterdi. Ancak, self-etch tekniği ile Clearfil SE Bond diğer adezivlerden daha iyi performans göstermiştir. Bu yüksek bağlanma dayanıkIllığı primer ve bond komponentlerinde bulunan yüksek konsantrasyondaki MDP monomerine bağlanabilir. ${ }^{25}$

Adezivlerin self-etch tekniği ile kullanılması kenar uyumunun zamanla bozulmasına sebep olabilir. Tek aşamalı self-etch adezivler genellikle iki aşamalı self-etch adezivlerden daha düşük performans göstermektedir. ${ }^{26}$ Tek aşamalı self-etch adezivler daha ince adeziv tabaka oluştururlar ve bu tabakalar oksijenle polimerizasyon inhibasyonuna daha eğimlidirler. ${ }^{2,27} \mathrm{Bu}$ çalışmada kullanılan tek aşamlı üniversal adezivler iki aşamalı Optibond XTR adezivle karşılaştırılığında benzer sonuçlar bulundu. Bu adeziv ajanların kimyasal kompozisyonlarının farklıı̆ı ile açıklanabilir.

Termal siklus klinik uygulamadaki biyomateryallerin fizyolojik yaşlanmasını simüle etmek için yaygın olarak kullanılan bir tekniktir. Rezin ve diş yapısının bağlanma ara yüzeyi boyunca döngüsel genişleme ve büzülme stresleri oluşturmaktadır. Sıcak suya batırılması aynı zamanda genişlemeye ve tamamen polimerize olmayan adeziv rezin monomerlerinin ortaya çıkmasına sebep olabilir. ${ }^{28}$ Bu çalışmada, termal siklus uygulaması 24 saatten sonra test edilen herbir adezivin mineye makaslama bağlanma dayanıkılığında herhangi bir farklıık oluşturmadı. Bu çalışmada uygulanan siklus sayısı (5.000) uzun dönem bağlanma etkililiğini simüle etmek için yeterli olmayabilir. Bu sebeple, üniversal adezivlerin bağlanma dayanımının değerlendirilmesinde yeni çalışmaların yapılması gerekmektedir.

$\mathrm{Bu}$ çalışmanın sınıları içerisinde test edilen adeziv ajanlarının fosforik asit ile uygulanması bağlanma dayanımını önemli derecede arttırmıştır. Termal siklus adezivlerin uygulama tekniğine bakılmaksızın bağlanma dayanımını etkilememiştir. Hem etch-andrinse hem self etch tekniği ile uygulanan üniversal adezivlerin bağlanma dayanımları arasında önemli bir farkllık bulunamadı. Self etch tekniği ile Clearfil SE Bond daha yüksek bağlanma dayanımı gösterdi.

Muhammet Karadaş, ORCID ID: 0000-0002-3357-6896

Ömer Hatipoğlu, ORCID ID: 0000-0002-4628-8551

Sabit Melih Ateş, ORCID ID: 0000-0001-7137-2096

\section{KAYNAKLAR}

1. Hanabusa $M$, Mine $A$, Kuboki $T$, Momoi $Y$, Van Ende A, Van Meerbeek B, De Munck J. Bonding effectiveness of a new 'multi-mode' adhesive to enamel and dentine. J Dent 2012;40:475-84.

2. Perdigao J. New developments in dental adhesion. Dent Clin North Am 2007;51:333-57.

3. Susin $A H$, Vasconcellos $W A$, Saad JR, Oliveira Junior $\mathrm{OB}$. Tensile bond strength of self-etching versus total-etching adhesive systems under different dentinal substrate conditions. Braz Oral Res 2007;21:81-6.

4. Van Meerbeek B, Yoshihara K, Yoshida Y, Mine A, De Munck J, Van Landuyt KL. State of the art of self-etch adhesives. Dent Mater 2011;27:17-28.

5. Nakabayashi N, Kojima K, Masuhara E. The promotion of adhesion by the infiltration of monomers into tooth substrates. J Biomed Mater Res 1982;16:265-73.

6. Perdigao J. Dentin bonding as a function of dentin structure. Dent Clin North Am 2002;46:277-301.

7. Erickson RL, Barkmeier WW, Kimmes NS. Bond strength of self-etch adhesives to pre-etched enamel. Dent Mater 2009;25:1187-94.

8. Bahari M, Savadi Oskoee S, Kimyai S, Pouralibaba F, Farhadi F, Norouzi M. Effect of Casein Phosphopeptide-amorphous Calcium Phosphate Treatment on Microtensile Bond Strength to Carious Affected Dentin Using Two Adhesive Strategies. J Dent Res Dent Clin Dent Prospects 2014;8:141-7. 
9. Pashley DH, Tay FR, Breschi L, Tjaderhane L, Carvalho RM, Carrilho M, Tezvergil-Mutluay A. State of the art etch-and-rinse adhesives. Dent Mater 2011;27:1-16.

10. Perdigao J, Lopes L, Lambrechts $P$, Leitao J, Van Meerbeek B, Vanherle G. Effects of a self-etching primer on enamel shear bond strengths and SEM morphology. Am J Dent 1997; 10:141-6.

11. Hannig M, Bock $H$, Bott $B$, Hoth-Hannig W. Intercrystallite nanoretention of self-etching adhesives at enamel imaged by transmission electron microscopy. Eur J Oral Sci 2002;110:464-70.

12. Tay FR, King NM, Chan KM, Pashley DH. How can nanoleakage occur in self-etching adhesive systems that demineralize and infiltrate simultaneously? J Adhes Dent 2002;4:255-69.

13. Perdigao J, Loguercio AD. Universal or Multi-mode Adhesives: Why and How? J Adhes Dent 2014;16:193-4.

14. de Goes MF, Shinohara MS, Freitas MS. Performance of a new one-step multi-mode adhesive on etched vs non-etched enamel on bond strength and interfacial morphology. J Adhes Dent 2014;16:243-50.

15. Erickson RL, Barkmeier WW, Latta MA. The role of etching in bonding to enamel: a comparison of self-etching and etch-and-rinse adhesive systems. Dent Mater 2009;25:1459-67.

16. Frankenberger $R$, Lohbauer $U$, Roggendorf $M J$, Naumann M, Taschner $M$. Selective enamel etching reconsidered: better than etch-and-rinse and self-etch? J Adhes Dent 2008;10:339-44.

17. Perdigao J, Geraldeli S. Bonding characteristics of self-etching adhesives to intact versus prepared enamel. J Esthet Restor Dent 2003;15:32-41.

18. Rosa WL, Piva E, Silva AF. Bond strength of universal adhesives: A systematic review and meta-analysis. J Dent 2015;43:765-76.

19. Barutcigil Ç, Barutcigil K, Kürklü D, Harorlı OT. Güncel dentin bağlayıcı ajanların ve uygulama yöntemlerinin makaslama bağlanma dayanımlarının karşılaştırıması. İnönü Üniversitesi Sağlık Bilimleri Dergisi 2013;2:27-32.

20. Chen $C$, Niu LN, Xie H, Zhang ZY, Zhou LQ, Jiao $\mathrm{K}$, Chen JH, Pashley DH, Tay FR. Bonding of universal adhesives to dentine--Old wine in new bottles? J Dent 2015;43:525-36.
21. Hayakawa T, Kikutake K, Nemoto K. Influence of self-etching primer treatment on the adhesion of resin composite to polished dentin and enamel. Dent Mater 1998;14:99-105.

22. Shinchi MJ, Soma K, Nakabayashi N. The effect of phosphoric acid concentration on resin tag length and bond strength of a photo-cured resin to acidetched enamel. Dent Mater 2000;16:324-9.

23. Yoshida $Y$, Nagakane K, Fukuda R, Nakayama $Y$, Okazaki M, Shintani H, Inoue S, Tagawa $Y$, Suzuki K, De Munck J,Van Meerbeek B. Comparative study on adhesive performance of functional monomers. J Dent Res 2004;83:454-8.

24. Milia E, Cumbo E, Cardoso RJ, Gallina G. Current dental adhesives systems. A narrative review. Curr Pharm Des 2012;18:5542-52.

25. Yoshida Y, Yoshihara K, Nagaoka N, Hayakawa S, Torii Y, Ogawa T, Osaka A, Meerbeek BV. Selfassembled Nano-layering at the Adhesive interface. J Dent Res 2012;91:376-81.

26. Akın GE, Hergüner-sıso Ş, Akın H. Termal siklus ve suda bekletmenin kendinden asitli adezivlerin dentine mikrogerilim bağlanma dayanimlari üzerine etkileri. Atatürk Üniv. Diş Hek Fak Derg 2012;22:125-31.

27. Nunes TG, Ceballos L, Osorio R, Toledano M. Spatially resolved photopolymerization kinetics and oxygen inhibition in dental adhesives. Biomaterials 2005;26:1809-17.

28. Morresi AL, D'Amario $M$, Capogreco $M$, Gatto $R$, Marzo G, D'Arcangelo C, Monaco A. Thermal cycling for restorative materials: does a standardized protocol exist in laboratory testing? A literature review. J Mech Behav Biomed Mater 2014;29:295-308.

\section{Yazışma Adresi}

Dr. Öğr. Üyesi Muhammet Karadaş

Recep Tayyip Erdoğan Üniversitesi,

Diş Hekimliği Fakültesi,

Restoratif Diş Tedavisi Ana Bilim Dalı

53100/Rize

E-mail: muhammet.2005@hotmail.com 